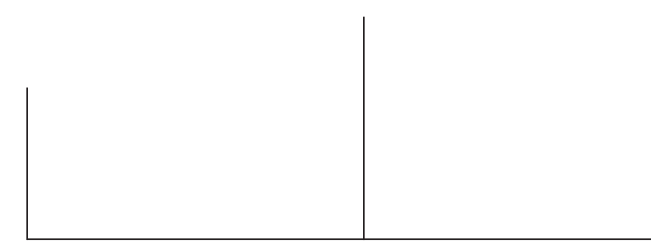

Rev. Latinoam. Psicopat. Fund., III, 3, 18-37

\title{
Sexualidade e preconceito
}

\author{
Paulo Roberto Ceccarelli
}

Retomando o debate sobre "sexualidade e preconceito", o texto discute por que a sexualidade continua sendo o grande enigma do ser humano. Embora tenham ocorrido tantas "evoluções", tabus e preconceitos em relação à sexualidade continuam a existir. Para lançar alguma luz sobre a questão, o autor faz uma rápida digressão histórica para contextuar o pensamento ocidental em relação à sexualidade desde os primórdios do Cristianismo até o surgimento do discurso psiquiátrico no século XIX. Em seguida, é analisado o impacto causado pela teoria psicanalítica neste pensamento.

Com base nas noções introduzidas pela psicanálise sobretudo o recalcamento e os ideais - a origem do preconceito é analisada e suas conseqüências debatidas seja no âmbito social como na clínica psicanalítica e na escuta do psicanalista.

Como forma de evitar o preconceito, o autor propõe que as manifestações da sexualidade sejam compreendidas como soluções particulares que cada ser humano tem de dar diante do enigma de sua própria organização pulsional.

Palavras-chave: Sexualidade, preconceito, perversão, ideais, recalque 


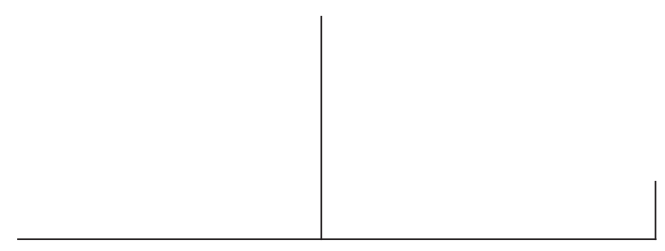

Os fatos da história, as interações entre a natureza humana, o desenvolvimento cultural e os precipitados das experiências primitivas não passam de um reflexo dos conflitos dinâmicos entre o ego, o id e o superego que a psicanálise estuda no indivíduo: são os mesmíssimos processos repetidos numa fase mais ampla.

Sigmund Freud

Introdução

Meu interesse ao retomar o velho debate sobre "sexualidade e preconceito" é saber por que a sexualidade continua sendo um grande enigma do ser humano. Por que, a despeito de tanta "evolução", ainda existem tantos tabus e preconceitos em relação à sexualidade? Se observarmos as diversas reações da atualidade em relação a certas atitudes de conotação sexual, ficaremos impressionados ao constatar que tais reações permanecem imutáveis ao longo da história. Assim, enquanto no passado havia uma preocupação excessiva, que pode nos fazer rir, com a questão do prazer, com os perigos da masturbação e outros tantos ligados à sexualidade, hoje, depois da "revolução sexual" da década de 1960, assistimos a acontecimentos, no fundo, bastante semelhantes: recentemente a mídia noticiou que uma professora de uma escola pública de São Paulo teria obrigado que um aluno de quatro anos lavasse a boca com sabão por ter beijado um colega. Nos USA um aluno de sete anos foi indiciado por assédio sexual por ter abraçado uma colega! O suplemento Teens da Folha de S. Paulo, de 18/10/99, publicou uma extensa matéria sobre um renomado colégio da Capital paulista que estava ameaçando de expulsão um aluno que se declarou homossexual e disse estar apaixonado por um colega. Por que o sexual desperta tanto terror podendo, às vezes, gerar atitudes absurdamente repressivas? Não se trata aqui, evidentemente, da sexualidade que se mostra explicitamente, mas, antes, daquela que desperta elementos recalcados evocando cenários inconscientes em quem vê a cena. Mas não é só esta forma de sexualidade que parece enigmática. Por que, à despeito de tantos movimentos, de tanta informação, as campanhas que incentivam o uso do preservativo, assim como aquelas 


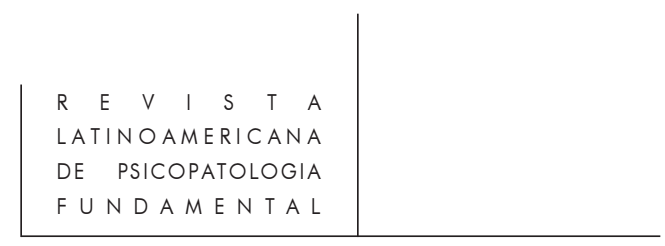

que procuram informar como evitar a gravidez na adolescência, são tão pouco eficazes? Que fatores inconscientes são despertados para que a atitude correta não seja tomada no momento em que isto se faz necessário?

Estas e outras indagações a respeito da sexualidade e suas manifestações levam a uma pergunta que pode ser formulada assim: seriam estas questões características da nossa época ou, ao contrário, trata-se das angústias próprias ao ser humano, vestidas com a roupagem característica do nosso momento histórico?

Em um trabalho anterior, ${ }^{1}$ apresentei, como um primeiro esboço de resposta, a hipótese de que a "desrepressão" da sexualidade não foi acompanhada de um "desrecalcamento" da sexualidade. Ou seja, por uma lado, temos a repressão sexual que por variar segundo a cultura, a época, os costumes e os valores, pode ser alterada; por outro lado, temos o recalcamento da sexualidade, movimento constitutivo do psiquismo e condição própria para a existência da civilização. Presente em qualquer época e em qualquer cultura, o recalque sofre pouca influência da desrepressão. Isto significa que uma maior liberdade sexual não tornou o contato com o sexual mais simples.

Neste texto, tentarei mostrar a relação entre os ideais, que participam ativamente nos movimentos do recalque, e a criação de uma sexualidade normativa cujo desvio gera, de um lado, o preconceito e, de outro, a culpa. Especificamente em relação ao preconceito, será interessante saber em que medida ele é parte constitutiva do psiquismo - e neste caso inerente à condição humana - e quando, ao contrário, o preconceito deve ser entendido como resultado de uma atitude moralista e redutora.

\section{Breve digressão histórica}

Para abordar o enigma do sexual, assim como a questão do preconceito, um pequeno desvio pela história da cultura ocidental - que não se pretende exaustivo poderá ajudar a elucidar alguns fatos. Não se trata de refazer uma "História da sexualidade, ${ }^{2}$ tarefa cumprida com mais competência por outros, mas apenas verificar alguns aspectos de como a sexualidade tem sido tratada ao longo da história, e as mudanças introduzidas pela ruptura psicanalítica.

O interesse desta digressão reside no fato de que o superego é, como Freud observa em vários de seus textos, formado não só pelo precipitado da autoridade paterna, mas também por fatores externos - os ideais - que pertencem ao sistema social em que o sujeito encontra-se inserido. As figuras que formam o superego e

1. P. R. Ceccarelli. O sexual da violência. Boletim de Novidades da Livraria Pulsional. São Paulo, Escuta. 11(106): 78-81, fev. 1998.

2. Conf. M. Foucault. Histoire de la sexualité. Paris: Gallimard, 1976. 3v. 


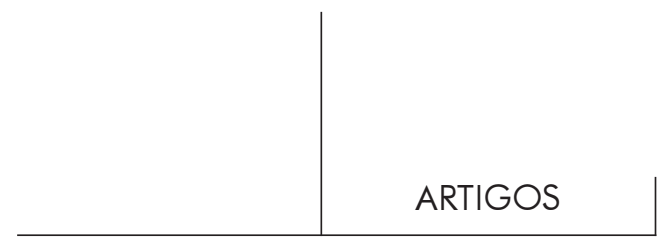

os ideais derivam do mundo externo. Estas figuras guardam as influências do passado e da tradição que, outrora, foram sentidas intensamente. ${ }^{3}$ Em nossa cultura ocidental, quais são os ideais em questão? Qual a participação da tradição judaico-cristã na formação destes ideais? Freud observa também que o impulso ao recalque deve-se "às exigências dos ideais estéticos e morais", ${ }_{4}^{4}$ que são fixados pela hereditariedade. Ou seja, a ontogênese reatualiza o capital filogenético dos ideais que foram estabelecidos como herança da cultura - a hereditariedade é uma aquisição cultural - tal como postulada em "Totem e tabu".

Embora as bases dos valores ético-morais de nossa cultura encontre suas raízes na tradição judaico-cristã, seria injusto atribuir ao Cristianismo o ascetismo em relação aos prazeres: o Cristianismo apenas preservou um legado que hostilizava o prazer e o corpo. ${ }^{5}$ Tal legado pessimista, que devia-se sobretudo a considerações médicas, ${ }^{6}$ tem suas origens na Antiguidade. Pitágoras recomendava que as relações sexuais ocorressem de preferência no inverno, embora o fazer sexo fosse prejudicial em todas as estações do ano. Hipócrates considerava que reter o sêmem proporcionava ao corpo a máxima energia; a sua perda, a morte. ${ }^{7}$ Segundo Sarano de Éfaso, médico pessoal do Imperador Adriano, o ato sexual só se justificava para a procriação.

Esta visão redutora do sexo foi, sem dúvida, intensificada por uma das maiores escolas da filosofia antiga - o estoicismo - cuja grande influência se deu entre $300 \mathrm{aC}$ a 250d.C. Toda importância que, de maneira geral, os filósofos gregos reservavam à busca do prazer, foi radicalmente transformada por esta corrente de pensamento que passou a concentrar a sexualidade no casamento. Este torna-se uma concessão àqueles que não podiam abster-se de relações sexuais; “... uma permissão para a satisfação da luxúria ou do prazer para aqueles que os consideravam indispensáveis". 8 Mais tarde, entretanto, o próprio casamento passa a ser questionado ao colocar-se a questão do prazer carnal no ato conjugal. Uma das mais fortes conseqüências disto foi a valorização do celibato.

3. S. Freud (1924). O problema econômico do masoquismo. In E.S.B. Rio de Janeiro: Imago, 1976. p. 209. v. XIX

4. S. Freud (1905). Três ensaios sobre a teoria da sexualidade. In E.S.B. Rio de Janeiro: Imago, 1972. p. 181. v. VII.

5. Não é minha intenção fazer uma análise histórico-crítica da história da Igreja Católica e de suas bases filosóficas. Meu interesse é apenas sublinhar alguns dos vários aspectos que, em nossa cultura, contribuem na formação dos ideais.

6. Toda a parte que se seguirá sobre a sexualidade na Antiguidade e no Cristianismo baseia-se no livre fundamental sobre o tema: "Eunucos pelo Reino de Deus". Cf. U. Ranke-Heinemann, Eunucos pelo Reino de Deus. 3a ed. Rio de Janeiro: Rosa dos Tempos, 1996.

7. U. Ranke-Heinemann. Op. cit., p. 22.

8. Ibidem, p. 23. 


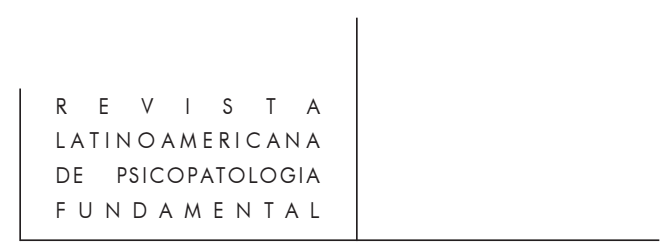

O negativismo em relação ao prazer sexual foi característica marcante do estoicismo nos dois primeiros séculos depois de Cristo e teve profunda influência no Cristianismo por meio dos grandes padres da Igreja - Agostinho, Jerônimo e Tomas de Aquino. O sexo é então vinculado à finalidade procriativa tendo como exemplo os animais, caso contrário trará o "estigma negativo do prazer". Vemos aí emergir uma forma de moralidade que é essencialmente moralidade sexual.

Outra corrente de pensamento que teve grande influência na moral cristã foi o gnosticismo que pregava que o mundo, mau como era, só poderia provir do demônio; que um Deus só poderia ter criado a alma. A única solução, pregavam os gnósticos, era o manter-se casto. Embora, sob vários aspectos, o Cristianismo tenha resistido ao pessimismo gnóstico, ele adota amplamente a idealização da castidade como algo mais próximo de Deus.

Também o judaísmo, que marcou profundamente a moral cristã, foi muito influenciado pela gnosticismo. Se, no Antigo Testamento, não existe uma visão negativa da sexualidade e a idéia central é de uma criação boa por um Deus bom, as descobertas em Qumrãn, no mar Morto, em 1947, mostram um panorama bastante diferente das seitas que habitavam o deserto no tempo de Jesus: estas são marcadas pelas idéias gnósticas e pela ascetismo sexual.

Dentre as muitas nações conquistadas pelos romanos, cuja religião teve grande 22 influência nesta cultura, estavam os judeus dispersos em pequenas comunidades espalhadas ao longo do Mediterrâneo. O segundo século d.C. foi marcado por pragas e epidemias, fatores que tiveram contribuição decisiva na queda do Império Romano. Neste sombrio ambiente de desespero e terror, o Cristianismo oferecia uma esperança nova em relação às outras crenças presentes na Roma antiga: a promessa de ressurreição após a morte como recompensa eterna para aqueles que, genuinamente, se arrependessem de seus pecados. Para os vivos, ainda mais: os milagres de Cristo e de seus seguidores. Estes eram sinais da intervenção divina que tinham o poder de curar e de desafiar a morte. Uma observação curiosa, mas não sem conseqüências, cabe aqui: os três evangelhos sinópticos de Mateus, Marcos e Lucas mencionam um certo número de milagres feitos por Cristo: vinte desses estão em Lucas - dois outros, o andar sobre as águas e o da figueira ardente, não estão. Dos vinte milagres citados por Lucas apenas três - o aplacamento da tormenta, a pesca milagrosa e a multiplicação dos pães - não são de origem médica: 11 milagres tratam de cura de doenças e invalidez; em quatro, demônios são expulsos; e em dois, mortos retornam à vida. No capítulo IX, versículo I do Evangelho de Lucas, lemos: "Jesus convocou os Doze e lhes deu poder e autoridade sobre os demônios e para curar doenças".

Sem dúvida, “... o crescimento da Igreja Católica foi estimulado pela sua missão especificamente médica em um contexto de pragas sucessivas". ${ }^{9}$ Formou-se assim 


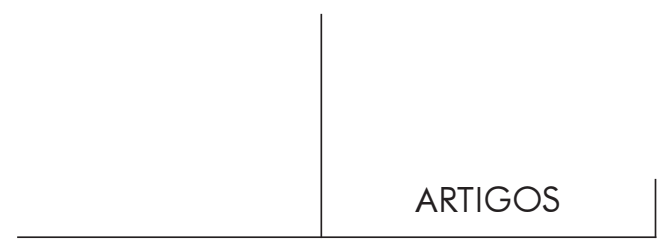

aquilo que se pode chamar do "culto de Cristo o Curador". Nesta perspectiva, Cristo pode ser considerado "... um dos maiores e mais bem-sucedidos fundadores de um novo sistema de medicina". ${ }^{10}$

As pequenas comunidades cristãs transformaram-se, na metade do terceiro século, na Igreja estabelecida que, em 313 d.C. foi oficializada por Constantino o Grande. Por volta desta mesma época, a prática da medicina passou para as mãos da Igreja; no império bizantino, médicos e sacerdotes confundiam-se e os cristãos continuaram a tradição judaica de cuidados caritativos de pobres e doentes, sob forma de enfermagem. As primeiras igrejas e os primeiros hospitais seguiam o mesmo plano arquitetônico: um altar central desembocando em duas ou quatro longas naves, ou áreas, das quais saíam pequenas capelas, cada uma dedicada a um santo. Nos hospitais, o tratamento estava nas mãos dos padres, assistidos por voluntárias que se transformariam, mais tarde, nas "irmãs de caridade". As doenças eram combatidas pela evocação de agentes sobrenaturais.

Uma das consequiências desta "filosofia" é evidente: a doença era um castigo, resultado do pecado, de uma falta na pureza da vida Cristã. A cura, se Deus assim o quisesse, só poderia ocorrer por intervenção divina. Tal cura, porém, não vinha apenas de Deus: como os semideuses da Roma pagã, os santos da Igreja Católica poderiam igualmente ser evocados para se alcançar um milagre. Tal perspectiva, de castigo e de cura, está presente até os nossos dias. Apenas um exemplo: o maior inimigo, o "vírus" mais difícil de combater no controle epidemiológico e na prevenção da disseminação do HIV, tem sido o preconceito cujas origens encontram-se na idéia, velha de mais de doi mil anos, de pecado e punição pela prática de uma sexualidade ilícita.

Foi esta tradição judaico-cristã, acrescida da concepção teológica de uma Natureza (physis) herdeira do pensamento grego, em particular de Aristóteles, que deu origem ao discurso que separa as práticas sexuais em "normais" e "anormais" (ou perversas, desviantes). ${ }^{11}$ Defende-se a idéia de uma sexualidade normal, conforme a natureza, cujo desvio, a depravação (pravus), ${ }^{12}$ é definido como "contra a natureza".

10. Ibid., p. 27.

11. Algumas passagens deste parágrafo e dos seguintes já foram apresentadas em um texto anterior. Conf. P. R. Ceccarelli. Potencialidades de perversão. Boletim de Novidades da Livraria Pulsional. São Paulo, 11(113): 79-82, set. 1998.

12. É somente a partir do final do século XIX e no século XX que o termo "perversão" tem sido usado em relação aos comportamentos sexuais que fogem à norma. Em sua origem, no sentido de uma "reversão", de um "retorno contra", o termo aparece pela primeira vez em 1444 derivado do Latim perversio. Sobre este ponto, ver o trabalho de Carlos Augusto Peixoto Júnior. Um breve histórico da perversão na sexologia do século XIX. Boletim de Novidades da Livraria Pulsional. São Paulo, 11(105): 34-49, jan. 1998. 


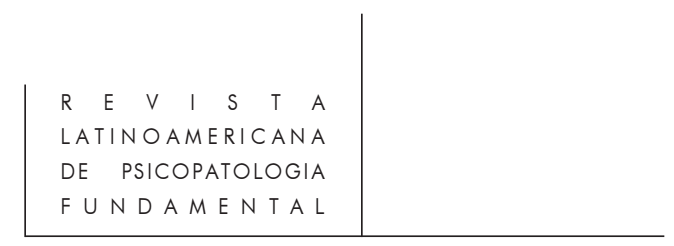

Sustenta-se que existem inclinações naturais nas coisas, e que tudo que é natural apraza a Deus, logo é bom. É nesta perspectiva que são Tomas de Aquino qualifica certas práticas sexuais de "contra a natureza", alegando uma natureza comum aos homens e aos animais. Assim, toda vez que a sexualidade desvia da finalidade primeira que a referência animal nos mostra - união de dois órgãos sexuais diferentes para a preservação da espécie -, estamos diante de uma perversão: pedofilia, necrofilia, masturbação, heterossexualismo separado da procriação, homossexualismo, sodomia...

É dentro deste espírito que a moralidade cristã, que "situa os principais pecados da humanidade nos quartos de dormir", ${ }^{13}$ desenvolveu-se. Toda a discussão do prazer no ato sexual, de como acontecia o ato sexual no Paraíso (onde não existia prazer sexual e onde, como os anjos, os homens se multiplicavam sem a reprodução sexual), dos perigos e pecados ligados à praticas sexuais "desviantes" e tantas outras posições repressoras, marcaram as bases "filosóficas" da Igreja dos primeiros séculos; bases estas que subjazem na formação dos ideais em nossa cultura.

Vamos encontrar este mesmo discurso teológico na origem das ações jurídicas destinadas a reprimir o ato dito perverso. As práticas "contra a natureza", que são consideradas um atentado ao pudor, aos bons costumes, e à opinião pública, acarretam severas sanções para que o "normal" seja mantido. Entretanto, a história assim o atesta, tal objetivo nunca foi alcançado: a sexualidade sempre escapou a toda e qualquer tentativa de normatização.

O discurso psiquiátrico contemporâneo só aparece na segunda metade do século XIX. Esse discurso, marcado por uma visão moralista, dá continuidade às posiç̃ôes teológicas e jurídicas, trazendo para a ordem médica o que, até então, era do jurídico. Os chamados "efeitos nocivos da sexualidade" - práticas contra a natureza, uma vida conjugal insuficiente, os perigos da masturbação, da contingência sexual, do coito interrompido... - eram discutidos em uma perspectiva higienista e repressiva. Os grandes psicopatólogos da época, dentre eles Havellock-Ellis e Krafft-Ebing, cujo valor é amplamente reconhecido por Freud, ocuparam-se em classificar e etiquetar as práticas sexuais que escapavam ao ditames morais. Talvez na tentativa - sempre frustrada e que tanto incomodava os psicopatólogos de então - de encontrar as "alterações" orgânicas responsáveis pelas "alterações" da pulsão sexual, traçou-se um minucioso inventário das perversões sexuais. Novas formas de perversões, em que o outro é usado para obtenção de prazer e a finalidade natural da sexualidade a procriação - é subvertida aparecem: voyeurismo, exibicionismo, sadismo, masoquismo vêm juntar-se à infindável nosografia psiquiátrica da época. 


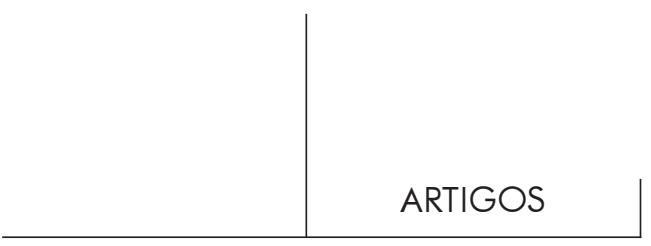

Termos que mais tarde tornar-se-iam clássicos em psicopatologia são aí introduzidos: perversão (1882, Charcot e Magna), narcisismo (1888, Havellock-Ellis), auto-erotismo (1899, Havellock-Ellis), sadismo e masoquismo (1890, Krafft-Ebing).

É também em meados do século passado que aparecem novas nomenclaturas numa tentativa de definir a especificidade de certas práticas sexuais; aquilo que hoje seria chamado de "direito à diferença". Por exemplo, em 1869 o médico húngaro Benkert ${ }^{14}$ cria o termo "homossexualidade", a fim de transferir do domínio jurídico para o médico esta manifestação da sexualidade. Entretanto, como observa Foucault, enquanto o sodomita era aquele que praticava atos jurídicos proibidos, o homossexual do século XIX “... transforma-se em um personagem: um passado, uma história e uma infância; uma morfologia também, com uma anatomia indiscreta e talvez uma fisiologia misteriosa. Nada de seu todo escapa à sexualidade... O homossexual transforma-se numa espécie". ${ }^{15}$ Estão aqui lançadas as bases para aquilo que em nosso século será acentuado: os comportamentos sexuais são transformados em identidades sexuais.

\section{A ruptura psicanalítica}

Ao criar a situação psicanalítica na qual “... a alienação torna-se desalienante porque, no médico, ela se torna sujeito", ${ }^{16}$ Freud rompe com a psiquiatria de sua época. Entretanto, ele vai ainda mais longe ao provocar uma virada profundamente inovadora. A publicação, em 1905, dos "Três ensaios sobre a teoria da sexualidade", que na época constitui apenas mais uma publicação dentre muitas outras, ${ }^{17}$ faz de Freud, nos conta Ernest Jones, uma figura "quase universalmente impopular". Ele recebe insultos e injúrias; não é mais cumprimentado na rua, sendo taxado de imoral, obsceno. Mas, o que havia Freud escrito, ou descrito, para provocar tamanha reação? Que revolução teria provocado?

A grande genialidade de Freud não vem do tipo de material clínico observado que, como vimos, fora exaustivamente classificados por seus predecessores, mas da afirmação escandalosa de que as tendências perversas catalogadas pelos seus colegas como aberrações humanas assombram o espírito de todos os homens -

14. E. Badiner. De l'identité masculine. Paris: Odile Jacob, 1992. p. 153.

15. M. Foucault. La volonté de savoir. Paris: Gallimard, 1976. p. 59.

16. M. Foucault. História da loucura. São Paulo: Perspectiva, 1978. p. 503.

17. Quando do lançamento dos Três ensaios sobre a teoria da sexualidade, o Psychopathia Sexuais de Krafft-Ebing - considerado como a grande referência no assunto pelos especialistas da época - está na sua $12^{a}$ edição, é traduzido em francês, inglês e italiano, e passou de 110 para 437 páginas! 
inclusive daqueles que as catalogaram - estando também presentes nas crianças: "a criança é um perverso polimorfo".

Ao introduzir a dimensão do desejo, que submetido às leis da linguagem escapa a qualquer apreensão direta de sua finalidade, Freud afirma que os desejos que os perversos põem em cena animam o inconsciente dos homens. ${ }^{18}$ Enquanto na neurose as pulsões agem na clandestinidade, disfarçadas de várias maneiras por meio dos sintomas, na perversão as pulsões inconscientes aparecem "a céu aberto": "a neurose é o negativo da perversão". O que vai diferenciar a sexualidade infantil da sexualidade perversa é que enquanto à primeira falta a centralização das pulsões parciais, esta centralização está, via de regra, presente na segunda. ${ }^{19}$

A tudo isto acrescenta-se um outro escândalo que mostra à biologia, à moral, à religião e à opinião popular o quanto elas se enganam no que diz respeito à natureza da sexualidade humana: a sexualidade humana é, sem si, perversa. (Perversa aqui entendida não no sentido psicanalítico, mas em seu sentido primeiro: desvio, depravação. O que caracteriza a perversão para Freud é a presença de uma organização psíquica baseada na recusa - Verleugnung.) Ao buscar o prazer, a sexualidade escapa à ordem da natureza e age a serviço próprio, "pervertendo", assim, seu suposto objetivo natural: a procriação. Entretanto, subordinar a sexualidade à função reprodutora é, segundo Freud, "um critério demasiadamente limitado. ${ }^{20}$ Nesta perspectiva, a sexualidade é contra a natureza; ou seja, em se tratando de sexualidade, não existe uma "natureza humana".

Ao mostrar que as perversões integram o psiquismo humano, Freud subverte o conceito de normalidade, fazendo dele uma ficção: não existe mais diferença qualitativa entre o normal e o patológico. A diferença entre a sexualidade perversa e a normal reside no fato de que "seus instintos componentes dominantes e, conseqüentemente, seus fins sexuais são diferentes". ${ }^{21}$

Baseando-se na visão da pulsão sexual diversificada, anárquica, plural e parcial - oral, anal, escopofílica, vocal, sádica, masoquista e tantas outras formas que ela pode tomar -, Freud propõe uma outra maneira de se pensar o sujeito, cuja constituição não pode ser separada da sexualidade, entendida aqui num sentido amplo. Freud estende assim a noção de sexualidade para além da fronteira da genitalidade, e abre a possibilidade de outras apresentações do sexual que têm um lugar considerável no psiquismo humano - o sexual dos ideais - tal como o amor pelos ideais, pelos líderes, pelos mestres.

18. “A se tratar cada homem segundo seu merecimento, quem escapará do açoite?" Hamlet, ato II.

19. S. Freud (1917). O desenvolvimento da libido e as organizações sexuais. Conferências introdutórias sobre a psicanálise. In E.S.B. Rio de Janeiro, Imago, 1976. p. 378. v. XVI.

20. Ibid., p. 375.

21. Ibid., p. 378. 


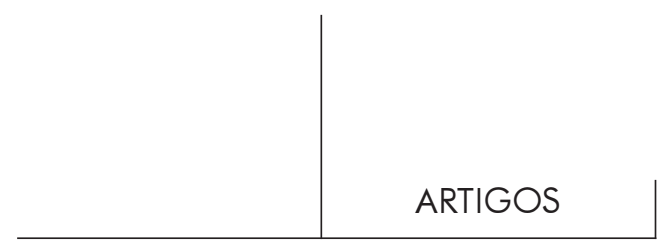

É esta forma de sexualidade que permite a compreensão dos fenômenos coletivos em que existe uma verdadeira ligação libidinal entre as massas e o líder; ela independe da diferença dos sexos e seu objeto é fictício, irreal, imaginário. O maior exemplo é fornecido pela situação amorosa, na qual “... o objeto serve de sucedâneo para algum inatingido ideal do ego em nós mesmos". ${ }^{22} \mathrm{O}$ vínculo entre os homens é também criado por esta forma de sexualidade; dela Lacan forja seu conceito de gozo, em que o ideal responde ao gozo do outro que, inicialmente, inscreve-se no sujeito quando ele reflete a imagem que corresponde ao desejo dos pais ou da família. ${ }^{23}$

Por ter como objeto algo inacessível, o sexual dos ideais pode ser alienante ao criar situações - por vezes perversas - nas quais o sujeito é apreendido numa malha imaginária anulando-se como sujeito. Temos aqui, por exemplo, a situação hipnótica que pode produzir-se entre uma teoria e um sujeito em busca da Verdade que aplacaria suas angústias; entre o Estado e seus membros; entre valores que são apresentados como referências identificatórias, tais como aqueles apresentados pela televisão, e a ilusão de que, possuindo estes valores, comprando determinados produtos, tornase parte de um grupo: obtém-se desta forma reconhecimento narcísico mantendose, ao mesmo tempo, a ilusão identitária. E a assim por diante.

Na clínica, o sexual dos ideais pode produzir efeitos perversos. Os complexos inconscientes infantis, que a transferência reatualiza, correm sempre o risco de provocar, entre analista e analisando, a instalação desta forma de sexual. Enquanto a sexualidade pré-genital, genital, ou ainda perversa, é facilmente detectável, o sexual sem nome que os ideais evocam pode fazer com que o sujeito, num narcisismo mortífero, entregue-se de corpo e alma ao gozo suposto do outro, que o analista encarna, levando-o a renunciar as modificações que conseguiu, graças à análise, para manter este lugar imaginário. A essência do trabalho analítico é a de descobrir, em cada caso, o procedimento adequado para que este tipo de sexual, ao invés de conduzir à uma nova forma de alienação, transforme-se numa força ativa que permita o sujeito fazer o luto das identificações. Quanto ao analista, cuja escuta não é imune a seus próprios complexos inconscientes e à sua própria organização identificatória, ele não está ao abrigo desta forma do sexual. Para tentar evitá-la, são necessárias "incursões repetidas" ${ }^{24} \mathrm{em}$ suas atitudes contratransferenciais para confrontar os

22. S. Freud (1921). Psicologia de grupo e análise do ego. In E.S.B. Rio de Janeiro: Imago, 1976. p. 143. v. XVIII.

23. Um estudo interessante sobre o "sexual dos ideais" foi feito por Gérard Bonnet. Le sexual freudien. In Les troubles de la sexualité. Monographies de la Revue Française de Psychanalyse. Paris: PUF, 1993.

24. J. McDougall. As múltiplas faces de Eros. Rio de Janeiro: Martins Fontes, 1997. p. 236. 


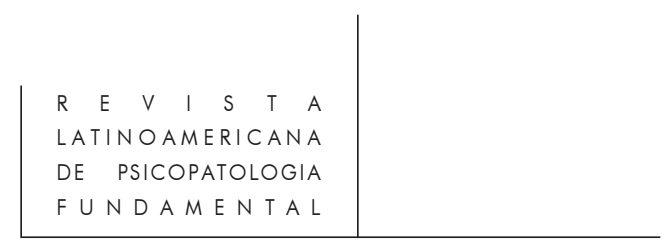

elementos neuróticos, perversos, psicóticos e normapáticos de sua sexualidade infantil.

Após Freud, diversos autores propuseram importantes idéias para se compreender o constituição do sujeito e sua sexualidade. De modo geral, os psicanalistas pós-freudianos seguem a perspectiva freudiana tanto em relação à perversão quanto à norma.

O trabalho de reflexão e teorização de Jacques Lacan sobre a obra de Freud trouxe, sem dúvida, uma das mais fecundas contribuições para a psicanálise, modificando sua inserção na cultura e a escuta clínica. Devemos a Lacan e seus discípulos o mérito de tirar a perversão do registro do desvio para apresentá-la como uma estrutura. ${ }^{25}$ Lacan entende a perversão como uma componente do funcionamento psíquico do homem, sendo que a estrutura perversa "se caracteriza pela vontade do sujeito de transformar-se em objeto de gozo". ${ }^{26}$

Vários autores contemporâneos - Robert Stoller, ${ }^{27}$ Joyce McDougall, ${ }^{28}$ Otto Kernberg, ${ }^{29}$ para citar apenas alguns dos mais conhecidos - fizeram importantes e inovadoras leituras críticas das posições clássicas de Freud em relação à perversão. Em linha direta freudiana, Joyce McDougall, por exemplo, sustenta que “... o único aspecto de uma fantasia que poderia legitimamente ser descrito como perverso seria a tentativa de impor a imaginação erótica a um outro que não consentisse nisso ou que não fosse responsável" ${ }^{30}$ McDougall utiliza, em vez de perversão, a expressão "neo-sexualidade" ${ }^{31}$ para descrever organizações psíquicas inovadoras resultantes de intensos investimentos libidinais. Com base na perspectiva teórica desta autora, a análise de algumas práticas sexuais ditas "patológicas" revelam que estas últimas representam não somente uma solução a fim de evitar sofrimentos psíquicos insuportáveis - uma forma de sobrevivência psíquica -, mas constituem também uma tentativa de construir um sentimento de identidade sexual. Certas práticas sexuais

25. J. Lacan. Kant avec Sade. In Écrits. Paris: Seuil, 1966. pp. 765-790.

26. Conf. E. Roudinesco e M. Plon. Dictionnaire de la psychanalyse. Paris: Fayard, 1997. p. 793.

27. R. Stoller. Recherches sur l'identité sexuelle. Paris: Gallimard, 1978. R. Stoller. The Transsexual Experiment. London: The Hogarth Press, 1975. R. Stoller. Perversion: the Erotic Form of Hatred. New York: Pantheon, 1976. R. Stoller. Observing Erotic Imagination. New Haven: Yale University Press, 1985. R. Stoller. Dynamiques des troubles erotiques. In Les troubles de la sexualité. Monographies de la Revue Française de Psychanalyse. Paris: PUF, 1993.

28. J. McDougall. Teatros do eu. Rio de Janeiro: Francisco Alves, 1992. J. McDougall. Em defesa de uma certa anormalidade. Artes Médicas: Porto Alegre, 1991. J. McDougall. As múltiplas faces de Eros. Op. cit.

29. O. Kernberg. Psicopatologia das relações amorosas. Porto Alegre: Artes Médicas, 1995.

30. J. McDougall. As múltiplas faces de Eros. Loc. cit., p. 192.

31. Ibid., p. 188. 


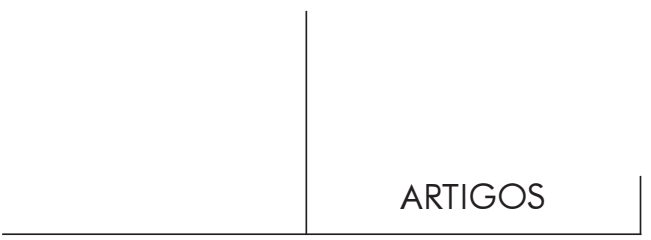

“perversas" podem, então, representar, para o sujeito, a única possibilidade de atividade sexual e, ao mesmo tempo, de construir um sentimento de identidade sexual.

\section{Os ideais e o preconceito}

Voltemos ao tema deste trabalho. Como já foi dito, Freud atribui grande importância aos ideais. Mas como eles se formam?

A questão dos ideais na obra freudiana é tratado em diversos textos. Em "Psicologia de grupo e análise do ego", os ideais são apresentados como formados por identificações segundo os modelos mais diversos. Fazem parte destes modelos as prescrições educativas da civilização que representam um "desenvolvimento" subjetivo necessário para o recalque do gozo.

É assim, por exemplo, que no estádio anal a criança tentaria manter o próprio corpo como objeto de gozo (brincar com os excrementos), o que traduziria sua tentativa de retorno ao narcisismo. Entretanto, diante da demanda da civilização (que aqui se confunde com o Outro), a criança deverá perder uma parte do seu corpo (neste caso seus excrementos), como foi o caso do seio no estádio oral. É por meio desta perda que a criança, segundo uma série de regras e ritos, terá acesso à lei de troca. Ocorre então, via recalcamento, a renúncia ao gozo narcísico de seu(s) odor(es) em detrimento dos odores culturalizados (pelo Outro): perfume, sabão, tabaco e outros tantos. ${ }^{32}$ Porém, e à despeito das satisfações substitutivas que a civilização oferece, a renúncia deste gozo será sempre incompleta, deixando na alma humana um sofrimento difícil de acalmar: este é o ponto de origem do "mal-estar" do qual sofre o homem. Ao mesmo tempo, Freud já havia observado nos "Três ensaios..." ${ }^{33}$ que as crianças parecem não incomodar-se com determinadas atitudes como, por exemplo, exibir seus corpos em público. Sentimentos tais como vergonha, repugnância, moralidade, só são apreendidos como valores culturais num segundo momento. Isto significa que, desde o início, as pulsões estão presentes de forma perversa-polimorfa e é apenas mais tarde que a criança aprenderá a controlá-las.

Entre 1927 e 1933, Freud consagra três textos, "O futuro de uma ilusão" (1927), "O mal-estar na cultura" (1929) e "Por que a guerra?" (1933), ao estudo do homem por meio do estudo das comunidades humanas. Freud sustenta que os processos presentes no desenvolvimento da civilização (registro da filogênese) assemelham-se aos da gênese do eu (registro da ontogênese); cabe à civilização dominar as forças da natureza (ao eu cabe dominar as excitações externas), assim como regular as

32. S. Freud (1930). O mal-estar na civilização. In E.S.B. Rio de Janeiro: Imago, 1974. v. XXI, cap. III.

33. S. Freud (1905). Três ensaios sobre a teoria da sexualidade. Loc. cit., p. 197. 


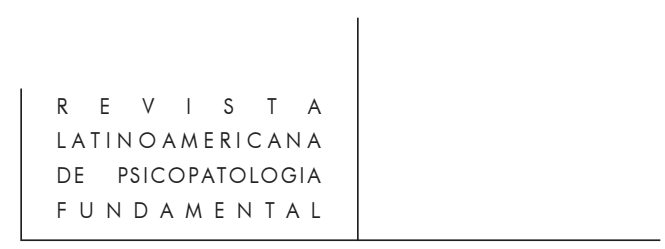

tensões internas entre seus membros (para o eu as excitações internas), próprias à sua organização. Mas o processo de resgate da filogênese na ontogênese que não é, em absoluto, fácil, pode ser gerador de neurose: “... as neuroses têm que prestar seu testemunho sobre a história do desenvolvimento da alma humana". ${ }^{34}$ A grande dificuldade reside no fato de que a criança deverá, em pouco tempo, "assimilar os resultados de uma evolução cultural que se estende por milhares de anos" ${ }^{35}$ para adaptar suas pulsões à cultura.

Segundo Freud, os impulsos sexuais do ser humano, a história do desenvolvimento da libido, repete, em parte, uma filogênese que é bem mais antiga que os impulsos do eu. No primeiro caso - impulsos sexuais -, haveria uma repetição das condições dos animais vertebrados; no segundo caso - impulsos do eu -, o que estaria em jogo seria a história da espécie humana, pois, evidentemente, só se pode falar em "eu" após o recalque. Isto significa que o desenvolvimento destas classes de impulsos seguem linhas diferentes e ocorrem em tempos diferentes, gerando conflito. Por outro lado, os impulsos sexuais podem, ao menos por certo tempo, ser satisfeitos auto-eroticamente, enquanto os impulsos do eu, desde o começo, não podem prescindir do objeto. Além disso, a certa altura do desenvolvimento da espécie humana, o homem primitivo, diante das ameaças à sua existência em virtude das mudanças do mundo externo, viu-se diante do conflito entre a autopreservação e a procriação. ${ }^{36}$ Teria, então, havido uma regressão da libido às "satisfações perversas" que, por não levarem à procriação, escaparam às proibições.

Conseqüentemente, haverá sempre conflito quando os impulsos sexuais, que nos vertebrados atuam sem censura, devem submeter-se às exigências da realidade (culturalização), ao superego, aos ideais. Ora, acredito ser exatamente na base deste conflito - mais precisamente do conflito entre as exigências pulsionais e os ideais constitutivos da cultura - que devemos procurar as origens do preconceito em relação ao sexual.

Com efeito, o que faz com que, em todos os tempos, assuntos referentes à práticas sexuais sempre gerem grandes polêmicas? O que existiria em comum entre, por exemplo, desejos necrófilos, práticas escotofágicas como meio de excitação, conversas telefônicas obscenas, e outras tantas manifestações da sexualidade que fogem à "norma"? Acredito que o ponto em comum tenha a mesma origem naquilo que, segundo Freud, faz com que a guerra seja tão intolerável: a guerra, e acrescentaria as "perversões", levam a um rebaixamento dos padrões estéticos.

34. S. Freud (1928). Neurose de transferência: uma sintese. Rio de Janeiro: Imago, 1987. p. 72.

35. S. Freud (1933). Explicações, aplicações e orientações. Novas conferências. In E.S.B. Rio de Janeiro: Imago, 1976. p. 180. v. XXII.

36. S. Freud (1928). Neurose de transferência: uma síntese. Loc. cit., p. 76. 


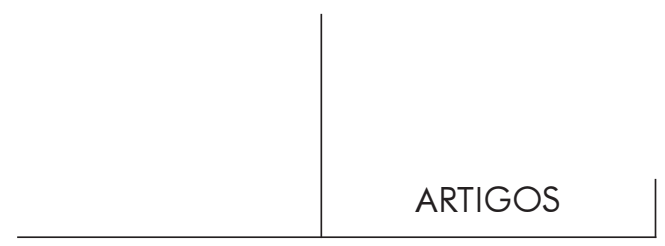

Para Freud, em seu texto magistral "Por que a guerra?", o longo processo civilizatório, que talvez “... esteja levando à extinção da raça humana, pois em mais de um sentido ele prejudica a função sexual", ${ }^{37}$ levou a inúmeras e notórias modificações psíquicas que limitaram as moções pulsionais. "Sensações que para os nossos ancestrais eram agradáveis, tornaram-se indiferentes ou até mesmo intoleráveis para nós; há motivos orgânicos para as modificações em nossos ideais éticos e estéticos". ${ }^{38}$ A guerra seria "a mais óbvia oposição" a estas modificações que o processo civilizatório tanto demorou para nos incutir. (Entretanto, é exatamente esta forma recalcada do sexual que faz retorno nas atrocidades da guerra em que vemos, às vezes transmitidas ao vivo pela $\mathrm{TV}$, atos de crueldade perpetrados entre aqueles que, até há bem pouco tempo, eram conhecidos, vizinhos, amigos...)

Este mesmo tipo de raciocínio pode ser ampliado e aplicado às "perversões". As renúncias pulsionais impostas pelo processo civilizatório não bastariam para inibir o retorno do sexual recalcado. E é aí que entram os ideais, que funcionariam como uma espécie de auxiliar no processo de recalcamento. Temos, então, dois movimentos simultâneos: o primeiro, presente na origem mesmo da história da espécie humana, diz respeito à renúncia do gozo narcísico em detrimento dos valores culturalizados, o que levou a grandes modificações psíquicas para que das moções pulsionais fossem recalcadas; o segundo movimento, em razão da pouca eficácia deste primeiro expediente, lança mão dos ideais para reforçar o recalcamento. Ao passarmos do registro do instinto para o da pulsão, a renúncia dos impulsos sexuais tornou-se problemática pois, como vimos, por não ter objeto fixo e estar submissa à dimensão do desejo, a pulsão escapa a qualquer forma de controle. Os ideais, que são construções culturais, serviriam para "direcionar", para normatizar aquilo que, de outra forma, seria percebido como ameaçador. Todavia, tal empreitada é, em sua essência, impossível, pois o sexual infantil está sempre pronto a fazer retorno nas situações mais inusitadas e nos momentos mais inesperados: os sonhos, os atos falhos, os sintomas, as fantasias mais secretas e os desejos mais inconfessáveis, as frustrações e as insatisfações que trazem as pessoas a nossos consultórios, tudo isto testemunha o fracasso tanto do recalcamento quanto da tentativa de criar-se uma sexualidade "ideal" que corresponderia a uma "natureza humana" que se pretende universal; onde este recurso falha, quando determinada expressão da sexualidade escapa ao recalque, ou não corresponde ao ideal, temos o preconceito.

O desprazer em virtude da ameaça de retorno das excitações recalcadas pode ser experienciado pelo sujeito como um objeto estrangeiro a si mesmo, gerador de ódio. Este "estrangeiro-interno" pode ser reativado a partir de excitações do mundo 


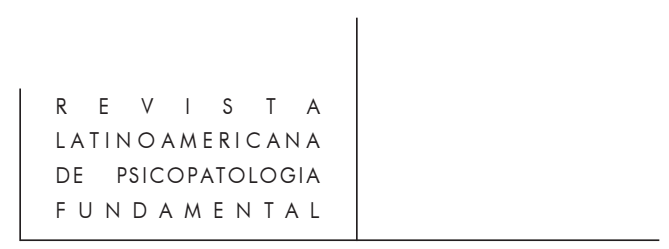

externo e ser vivenciado pelo sujeito como uma ameaça. A fantasia subjacente seria a de que sem a norma, sem a regra que viesse fazer barreira ao pulsional, correrse-ia o risco de perdermos o controle, de sermos invadido pelo retorno do recalcado. Daí as restrições, os princípios éticos-morais, e as punições, que variam, tanto quanto os ideais, segundo as diferentes culturas. Nesta linha de raciocínio, uma primeira expressão do preconceito pode ser postulada: ele seria, por assim dizer, o outro lado do recalque, uma espécie de mecanismo de defesa inerente à construção do psiquismo, portanto universal. Isto significa que o preconceito funcionaria como um alerta - uma forma mais sofisticada da angústia sinal? - contra moções pulsionais recalcadas que ameaçam os padrões estéticos. Mas há também manifestações de atitudes segregadoras às quais damos igualmente o nome de preconceito. Esta outra forma de preconceito, que pode ser expresso como "aquele não pensa como eu, que é diferente, é meu inimigo", aparece quando o referencial de valores do outro difere do meu, o que, sem dúvida, evoca igualmente moções recalcadas, mas, desta feita, ligadas aos ideais. Entretanto, os movimentos psíquicos, cuja falha gera o preconceito, têm pouca eficácia defensiva pelo paradoxo que criam: se, por um lado, as perversões sexuais são sentidas não apenas como algo repulsivo, mas, igualmente, como alguma coisa monstruosa e perigosa, por outro lado, as pessoas as sentem como sedutoras e, no fundo, têm de "sufocar uma secreta inveja daqueles que as experimentam". ${ }^{39}$ Quanto ao sentimento de culpa, ele aparece quando existe uma tensão entre o eu e o ideal; quando o sujeito não corresponde àquilo que dele se espera. Por isto pode ocorrer, às vezes, que o sujeito que é vítima do preconceito, experimenta este mesmo preconceito e, ao mesmo tempo, tem culpa.

$\mathrm{O}$ preconceito gerado pelas diferenças dos ideais pode ser mais claramente apreciado nas diversidades culturais.

Em nossa cultura ocidental, como vimos, a tradição judaico-cristã influenciou fortemente a criação dos ideais e, conseqüentemente, aquilo que seria "normal" em termos de sexualidade: é normal a sexualidade, que a referência animal nos mostra, dedicada à preservação da espécie. Entretanto, estudos sócio-antropológicos são ricos em exemplos de como certas práticas, em nossa tradição consideradas perversas, (é importante insistir, mais uma vez, que não se trata aqui de perversão tal como a psicanálise entende este termo; estamos falando dos ideais) possuem, em outras culturas, outras leituras. Bem perto de nós, em algumas nações indígenas, temos práticas que vão neste sentido, como, por exemplo, o travestismo em certas tribos que já em 1817 chocara Karl Friedrich Philipp von Martius, naturalista bávaro que realizou pesquisas no Brasil. Em outras tribos, como os índios Kraô, um subgrupo cultural dos Timbiras no norte do estado de Goiás, a agressividade é pouco 


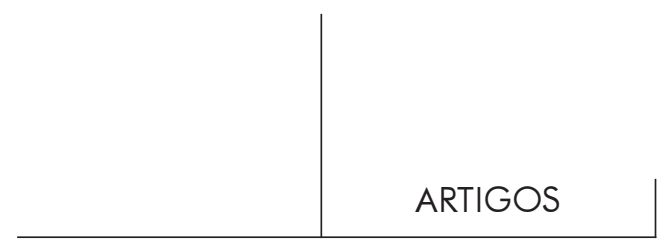

incentivada, e a cordialidade cultivada. Para estes índios, a valentia é vista como negativa. ${ }^{40}$ Os homens da tribo demonstram muito mais afetividade entre si do que com as mulheres. Os solteiros dormem juntos com a cabeça recostada ou no peito ou nos ombros uns dos outros. A prática de "fazer cunin", fazer sexo, é muito comum e explícita principalmente entre os solteiros de 15 a vinte anos. ${ }^{41}$

(Os portugueses, quando chegaram ao Brasil, ficaram horrorizados ao ver os índios nus e ao constatar como eles lidavam com a sexualidade. A expressão utilizada traduz bem o impacto: "devassos no paraíso". O choque, pelo menos no lado português, foi um choque de ideais. Jamais teria lhes ocorrido que os índios - ou alguém - pudessem pensar diferente, o que deve ter sido altamente ameaçador para os elementos recalcados da sexualidade dos colonizadores! Ainda sobre colonizadores e colonizados, há uma passagem que ilustra que não é só em relação à sexualidade que o preconceito se mostra. Os espanhóis, no México, qualificaram de barbaridade a prática Asteca de arrancar, ainda pulsando, os corações dos vencidos em sacrifícios aos deuses. Entretanto, estes mesmos espanhóis não tiveram o mesmo constrangimento de aniquilar toda uma cultura em nome de seus ideais.)

Gérald Bonnet, ${ }^{42} \mathrm{em}$ um trabalho recente, apresenta uma hipótese que corrobora nossa idéia da importância dos ideais na tentativa de adestramento da pulsão. Estudando os trabalhos de Leroy Gourhan sobre as pinturas do paleolítico, Bonnet observa a impressionante predominância de casais de animais, ou seja, de acasalamento heterossexual, nessas pinturas. Segundo Bonnet, este interesse seria uma busca de um "espelho" para a vida sexual. Nossos ancestrais teriam, então, introjetado, via identificação, este aspecto da vida dos animais. ${ }^{43}$ Para este autor, estaria aí a origem do ideal heterossexual e monogâmico dominante em nossa sociedade. Ou seja, seguindo a nossa hipótese, uma maneira de normatizar a pulsão, de tentar dar-lhe um objeto fixo.

40. Em um texto no qual discuto a questão da construção da masculinidade, tive oportunidade de falar sobre os ideais que governam as práticas de iniciação entre Sambia da Nova Guiné e entre os Semai, na Malásia central. Conf. P. R. Ceccarelli. A construção da masculinidade. Percurso. São Paulo. Instituto Sedes Sapientiae. 19: 49-56, 1998.

41. Sobre as práticas sexuais entre os indígenas e sobre a questão da homossexualidade no Brasil, consultar o livro de referência sobre o assunto "devassos no paraíso". Cf. J. S. Trevisan. Devassos no paraíso: a homossexualidade no Brasil, da Colônia à atualidade. São Paulo: Max Limonad, 1986. Obs.: uma nova edição atualizada e consideravelmente ampliada estará disponível pela Ed. Record, Rio de Janeiro, em janeiro de 2000.

42. G. Bonnet. A roda gira: sobre o transexualismo e a homossexualidade. In P. R. Ceccarelli (org.). Diferenças sexuais. São Paulo: Escuta, 1999. pp. 27-52.

43. Estudos recentes mostram que os animais não são tão "normais" quanto se pensa. Conf. B. Bagemihl. Biological Exuberance - Animal Homosexuality an Natural Diversity. New York: St. Martin's Press, 1999. 
O interesse em citar, ainda que de forma bastante reduzida, fontes antropológicas e pré-históricas é o de mostrar que os ideais são construções dependentes das formas culturais dentro das quais eles emergem: cada sociedade construirá seus ideais, que ditarão o que é normal e anormal, ou perverso, em termos de sexualidade. ${ }^{44}$ Se bem que o "mundo natural" seja o mesmo para todos, não existe, a partir daí, um paradigma único: a maneira como cada sociedade vai, num primeiro momento, decompô-lo e apreendê-lo para, em seguida, recompô-lo, varia enormemente. ${ }^{45}$ As associações sintagmáticas criadas para "ler o mundo", e a conseqüente criação dos ideais, refletem o sistema simbólico da sociedade em questão, e estão sujeitas ao universo imaginário e fantasmático desta mesma sociedade. Cada sociedade cria, a partir do sistema representativo que lhe é próprio, as representações dos ideais, e falar de natureza no homem é tão absurdo quanto falar de obsceno no animal: a verdadeira natureza do homem é a cultura e é na proibição do incesto regulação da qual o conceito lacaniano de Lei tira toda a sua força - que encontramos aquilo que é universalmente específico a todos os homens.

Resumindo: onde existe sexualidade, há preconceito; os ideais traduzem tentativas de criar uma norma - a "natureza humana" - para enquadrar, para controlar, para direcionar as pulsões; o preconceito, em suas diversas expressões, demonstra a insuficiência deste recurso e denuncia a falência da barreira criada para manter afastada da consciência aquilo que ameaça de dentro e que abala os valores estéticos e morais: o retorno da moções pulsionais - anárquicas, plurais e parciais - em busca de satisfação. O sentimento de culpa apareceria toda vez que houvesse uma tensão - negativa - entre o eu e o ideal.

\section{Manifestações da sexualidade: problemas ou soluções?}

Os ideais se prestam a normatizar as pulsões, e a importância de valores estéticos-morais tanto para este fim quanto para a existência da civilização é inegável. Embora a criação de ideais seja um processo necessário inerente à espécie humana, existe uma grande diferença entre tratar os ideais como construções culturais, ou seja, dentro de referências imaginárias, e tratá-los como verdades. Igualmente importante é distinguir quando o preconceito resulta de uma ameaça do retorno do recalcado, e quando deriva de diferenças entre valores morais que, como vimos, variam segundo as culturas.

44. Foge ao escopo deste trabalho, embora seria sem dúvida interessante, discutir os ideais de outras sociedades e suas relações com as limitações das moções pulsionais.

45. Um interessante estudo sobre a questão das "apreensões" do mundo é o de Françoise Héritier. Masculin/féminin: la pensée de la différence. Paris: Odile Jacob, 1996. 


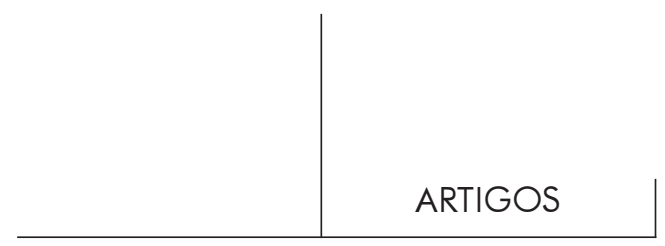

Dentro da dimensão específica da psicanálise - que vem justamente mostrar o quão ilusório é falar de "normal" em se tratando de pulsão -, o relevante é tentar compreender a dinâmica das diversas manifestações da sexualidade. Para isto, visto que os padrões da sexualidade humana são criados e não inatos, é necessário levar em conta a singularidade da história de cada um, lembrando que esta história é construída por meio da sedimentação de identificações sucessivas em diversos níveis (simbólico, imaginário e fantasmático), resultado de encontros deste sujeito com outros sujeitos significantes.

Nesta perspectiva, mais do que discutir a normalidade ou a patologia de determinada expressão da sexualidade, o que interessa é determinar os movimentos pulsionais e os processos identificatórios que levaram à construção daquela dinâmica psicossexual particular. Devemos contentar-nos, seguindo o conselho de Freud, em “... revelar os mecanismos psíquicos que culminaram na determinação da escolha de objeto, e remontar os caminhos que levam deles até as disposições instintuais". ${ }^{46}$ Isto significa que as manifestações da sexualidade, tanto as "normais" quanto aquelas que fogem à norma, devem ser compreendidas não como problemas, mas, antes, como soluções. "Soluções" às comunicações verbais e pré-verbais dos pais, que podem ser contraditórias, a respeito dos elementos constitutivos da sexualidade; ao lugar que se espera que a criança ocupe na dinâmica familiar, assim como os ideais que se espera que ela responda o que pode representar, em alguns casos, uma tentativa (perversa?) de elaboração de lutos e feridas narcísicas sempre presentes no inconsciente dos pais; enfim, soluções às variáveis que acolhem a criança quando de seu nascimento e a interação destas últimas com os fatores constitucionais inatos.

Escutar os problemas como soluções significa adotar como valor fundamental a "necessidade de garantir a sobrevivência psíquica" 47 e não nos esquecermos, ao mesmo tempo, que a nossa escuta clínica não é insensível aos nossos valores pessoais (ideais, preconceitos e culpa), pois, como já dissemos, o analista não é imune a seus próprios complexos inconscientes e à sua organização identificatória.

Esta posição ética, que "respeita o enraizamento necessário de cada ser humano na realização de sua vida", ${ }^{48}$ é bastante próxima da proposta da Psicopatologia Fundamental, tal como descrita por Manoel Berlinck. ${ }^{49}$ Dispondo-se a escutar um sujeito que fala de seu sofrimento, de suas paixões, de seu pathos, a Psicopatologia

46. S. Freud (1933). A psicogênese de um caso de homossexualismo numa mulher. In E.S.B. Rio de Janeiro: Imago. p. 211. v. XVIII.

47. J. McDougall. As múltiplas faces de Eros. Loc. cit., p. 263.

48. L. Boff. A águia e a galinha: uma metáfora da condição humana. 29a ed. Petrópolis: Vozes, 1999. p. 93.

49. M. T. Berlinck. O que é psicopatologia fundamental. Revista Latinoamericana de Psicopatologia Fundamental. São Paulo. 1(1): 46-59. 


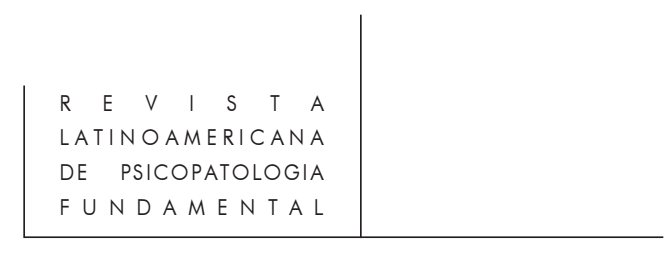

Fundamental transforma a narrativa do sujeito. Por não ocupar o lugar do orthos, do correto, da ortodoxia, a Psicopatologia Fundamental vai especificar uma posição teórico-clínica que se propõe, baseada na ruptura freudiana, a "criar" uma psicopatologia própria para cada sujeito que lhe permita transformar em experiência as manifestações de seu pathos. (Seria interessante, mas isto fica para um outro trabalho, pensar as interações e inter-relações entre a proposta de Psicopatologia Fundamental e a escuta das sexualidades "desviantes".)

Trabalhar nesta perspectiva é reconhecer que as manifestações da sexualidade, por mais "desviantes" que possam parecer, traduzem uma criação particular e única de cada sujeito; é lembrar que o aspecto mais notável dos seres humanos é a singularidade psíquica, assim como a genética, de cada um. É também não esquecer que a sexualidade constitui o enigma por excelência do ser humano; que este se escalona em diferentes registros, contendo formas de prazer diversos, múltiplos e, por vezes, inconciliáveis. Tal como Édipo diante da esfinge, a cada um cabe tentar responder ao enigma que sua própria sexualidade lhe impõe - resposta esta que é única como é único cada ser humano.

36

\section{Resumos}

Reanudando el debate sobre "sexualidad y prejuicio", el texto discute porque la sexualidad sigue siendo el grande enigma de lo ser humano. Sin embargo, tengan ocurrido tantas "evoluciones", tabus y prejuicios respecto a la sexualidad siguen a existir. Para lanzar alguna luz sobre la cuestión, el autor hace una rapida digresión histórica para contextualizar el pensamiento occidental respecto a la sexualidade desde los comienzos del Cristianismo hasta el surgimento del discurso psiquiatrico en el siglo XIX. Despues es analisado el impacto causado por la teoría psicoanalitica en este pensamiento.

Com base en las nociones traducidas por la psicoanálisis - la origen del prejuicio es analisada y sus consecuencias debatidas sea en el ámbito social cómo en la clinica psicoanalitica y en la escucha del psicoanalista.

Como forma de evitar el prejuicio, el autor propone que las manifestaciones de la sexualidad sean comprendidas como soluciones particulares que cada ser humano tiene de dar enfrente del enigma de su propia organización pulsional.

Palabras llave: Sexualidad, prejuicios, perversions, ideales, represión

Reprenant le débat "Sexualité et préjugé", le texte pose la question de savoir pourquoi la sexualité est toujours un grand énigme pour l'être humain. Malgré de nombreuses "évolutions", les tabous et préjugés par rapport a la sexualité sont encore lá. 


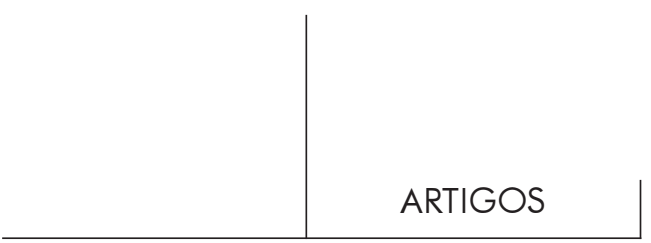

Pour essayer de lancer quelque lumière sur la question, l'auteur fait un survol rapide sur l'histoire afin de situer la pensée occidental par rapport à la sexualité dès le début du Christianisme jusqu'à la naissance du discours psychiatrique du XIX Siècle. En suite, il analyse l'impact de la théorie psychanalytique sur ce discours. À partir des notions introduites par la psychanalyse - surtout celle du Refoulement et des Idéaux - l'origine du préjugé est analysée. Les conséquences qui en sortent sont débattues dans la dimension sociale, dans la clinique et dans l'écoute psychanalytique.

Finalement, l'auteur remarque que les manifestations de la sexualité doivent être comprises comme des solutions particulières que chacun trouve face au énigme posé par sa propre organisation pulsionnelle.

Mots clés: Sexualité, préjugé, perversions, Idéaux, refoulement

This text brings up the debate on "Sexuality and prejudice" to show that sexuality remains a profound enigma for human beings. Despite the many "evolutions", taboos and prejudice concerning sexuality still persist.

In oder to throw some light onto the question, the author makes a short historical review of occidental thought on sexuality since the beginning of the Christian Era up to the onset of the Psychiatric Discourse of the XIX Century. Then, the impact of Psychoanalytic theory on this School of Thinking is analysed. Based upon important psychoanalytical concepts - such as Repression and the Ego Ideals - the origins of prejudice are studied and their consequences discussed from both their social and clinic aspects.

The author points out that all sexual manifestations should be seen as private solutions that each particular Human being had to find in order to face the enigma of his, or her, own drive organisation.

Key words: Sexuality, prejudice, pervertions, ideals, repression 